\title{
IMPROVING AWARENESS AND UNDERSTANDING OF MANAGING LOCAL ANAESTHETIC TOXICITY AMONG HOSPITAL TEAM MEMBERS
}

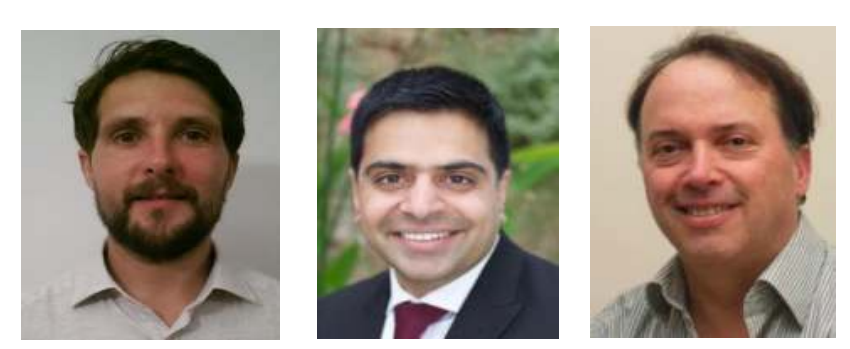

\begin{abstract}
F. Gill1 (Foundation Year 2), M.A. Qureshi' ${ }^{1}$ (Regional Anaesthesia Fellow), F. Sage (Consultant in Anesthestics \& ITU).
${ }^{1}$ Anaesthetic and Pain Department, East Surrey Hospital, Redhill, United Kingdom
\end{abstract}

Introduction: Local anaesthetics (LA) are delivered by a variety of different healthcare professionals this occurs on a regular basis in hospitals. There have been reported cases of accidental overdoses, which have led to the death of patients ${ }^{1}$. Therefore a sound knowledge of the delivery and complications of LA is required by all those who may use them. We investigated the level of understanding amongst healthcare professionals about the local anaesthetic drugs used in our hospital and their toxicity. We aimed to improve awareness and deliver an educational programme in accordance with the guidelines issued by the AAGBI ${ }^{2}$ (Scan QR code below).

Method: An online survey was designed and then approved by the local audit committee. The questionnaire (fig 1) looked at safe concentration, early and late signs, initial management and identifying the location of intralipid in the hospital. The survey was intended for all health care professionals working in the hospital. Responses were acquired from a variety of departments including surgery, anaesthetics and A\&E; and from medical grades ranging from foundation doctors to consultants.
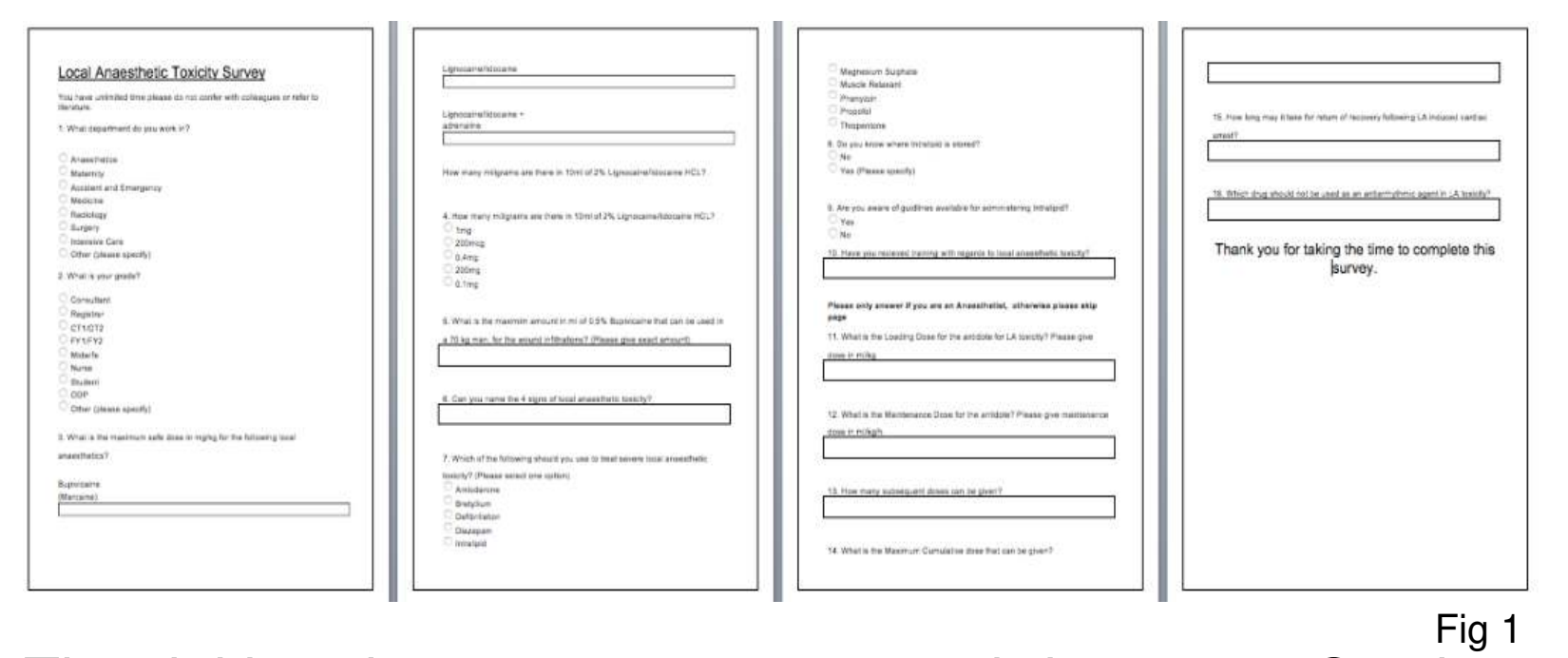

The initial data set was collected between OctoberDecember 2017 (Survey 1). An education programme was then implemented which involved a number of online educational materials and teaching to improve understanding (fig 2). The second data set was then collected in February-April 2018 (Survey 2), which allowed us to evaluate the impact of our intervention.
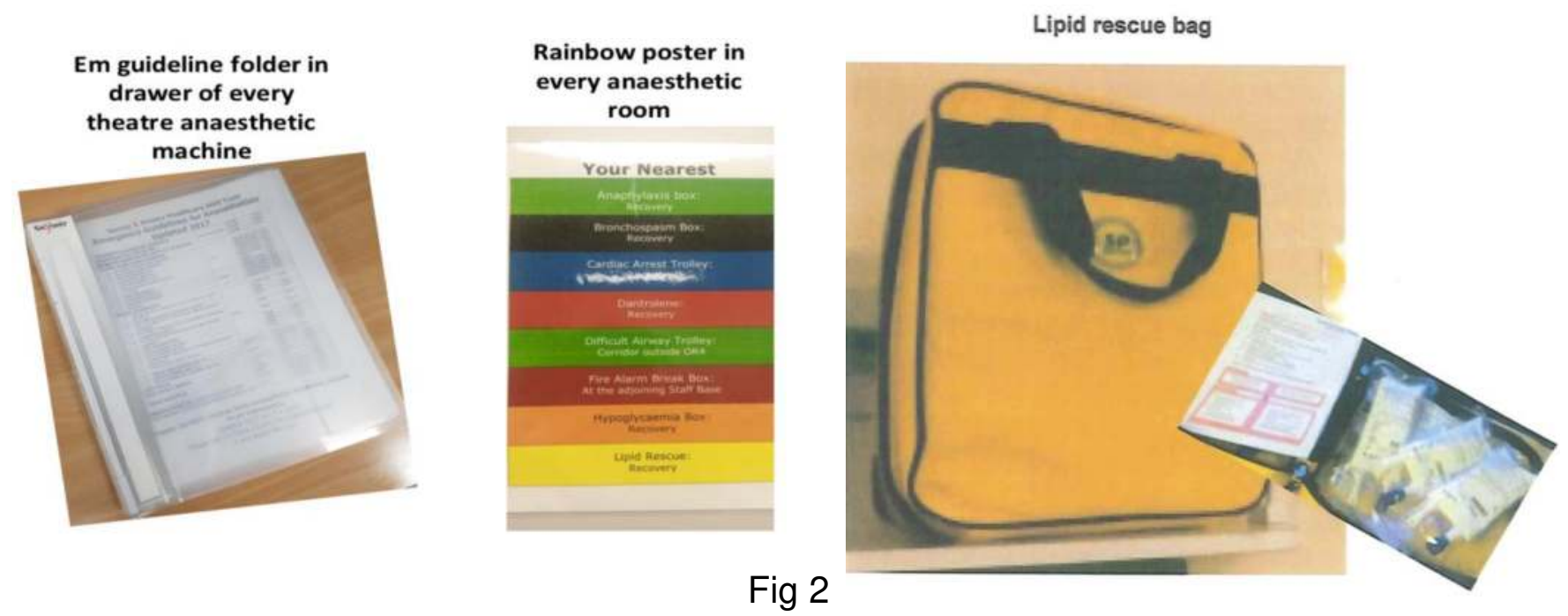

\section{References:}

Fig 2
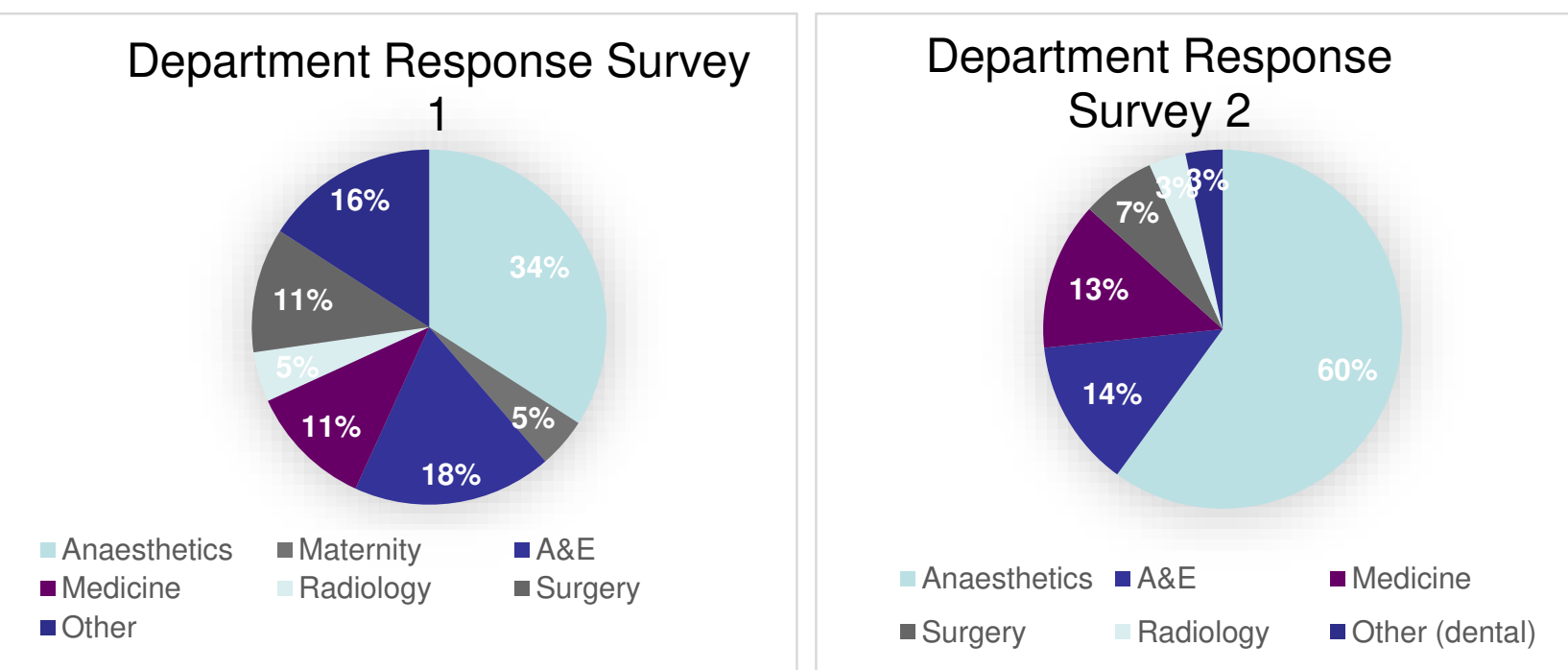

Correct Maximum Doses of LA
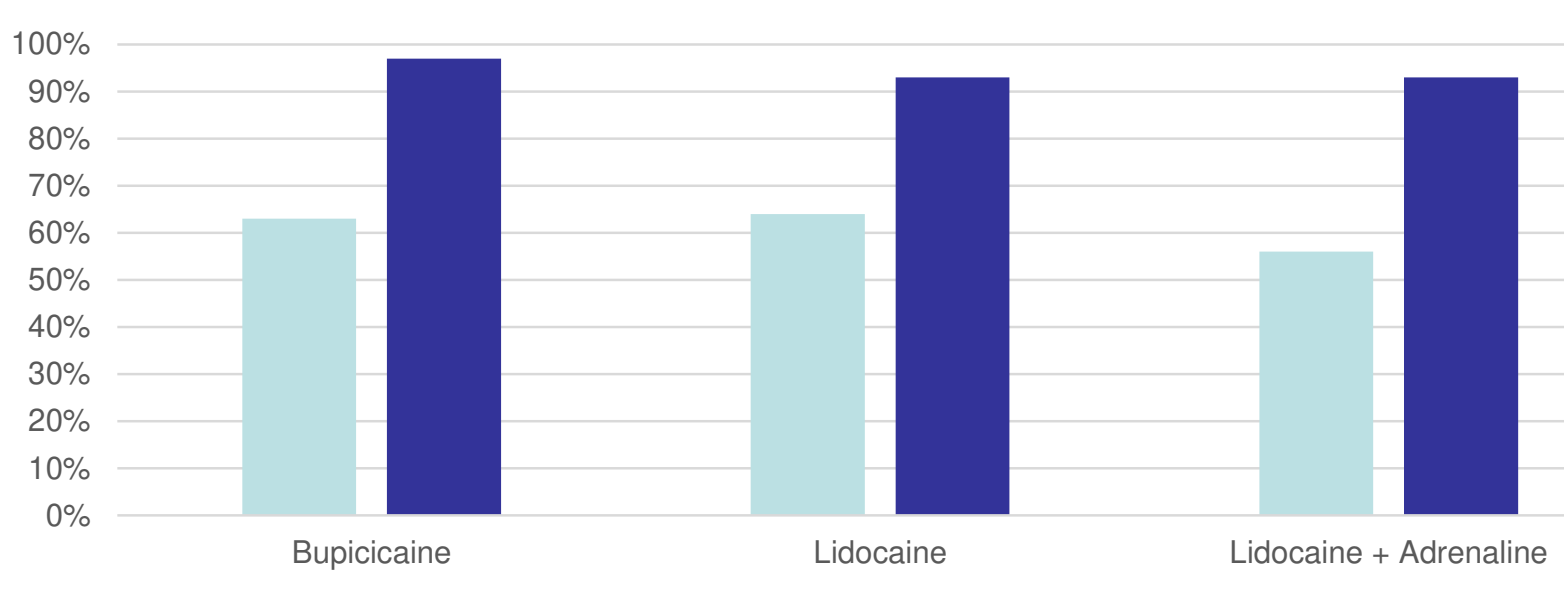

- Oct. - Dec. - Feb. - Apr.

Fig 3

Correct Signs of LA Toxicity

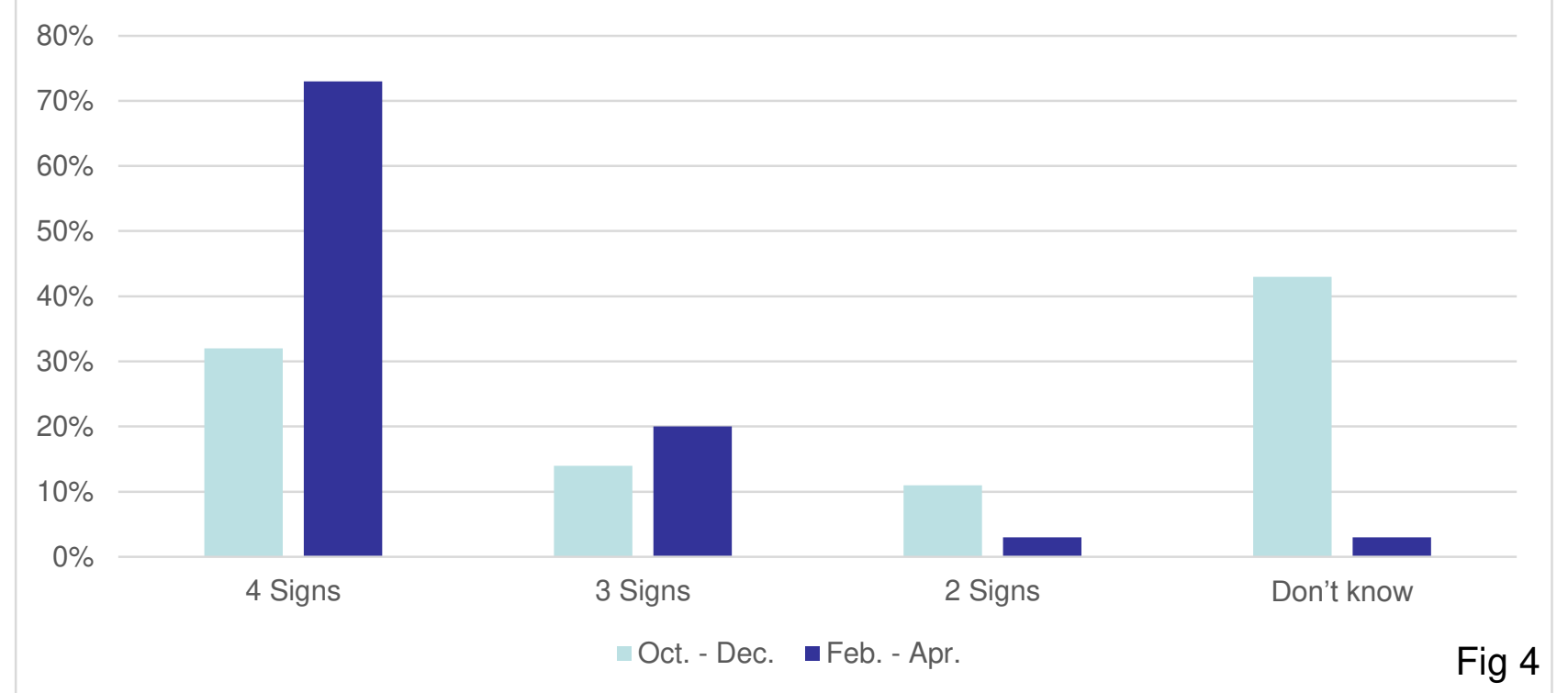

Results: There were 44 responses from survey 1 and 30 from survey 2 . The delivery of a focused educational programme showed significant improvements in the knowledge of safe LA doses (fig 3) (65\% to $>95 \%$ ), correct dose calculations for LA ( $41 \%$ to $83 \%$ ), identification of signs of LA toxicity (fig 4 ), treatment of LA toxicity (85\% to $97 \%$ ) and location of intralipid storage $(52 \%$ to $70 \%)$.

Discussion: Despite the widespread use of LA in the hospital by a number of different healthcare professionals the knowledge and awareness of its risk is not shared between all. The delivery of an education programme was well received and did show improvement in certain groups. However, with a dynamic workforce maintaining this level of knowledge is challenging. Further education and the development of a course, which would form an integral part of compulsory training, should be considered for all those who deliver LA regularly as part of their practice.

This Project was carried out as part of the Regional Anaesthesia Fellowship at East Surrey Hospital.

1. The Guardian. 5th Feb 2008. Drug storage at hospital was 'chaotic'. Sub-standard storage of drugs at hospital contributed to mother's death. http://www.theguardian.com/society/2008/feb/05/nhs. health2 